\title{
sit
}

\section{Ludwig Eduard Boltzmann (1844-1906)}

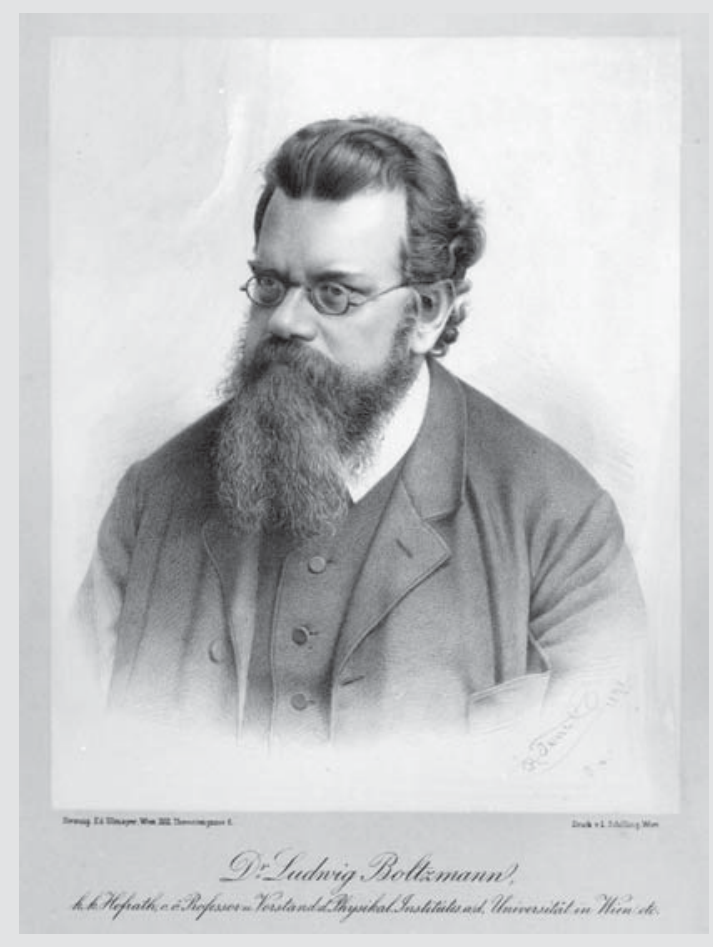

\section{Modelo}

ModeLo (do fr. ant. modelle, mod. modèle; do it. modello, padrão, molde; do lat. modus, medida, padrão), uma representação tangível - em tamanho igual, maior ou menor de um objeto que tenha existência real ou que tenha sido construído de fato ou em pensamento. De maneira geral denota uma coisa que pode existir realmente ou ser apenas concebida mentalmente, cujas propriedades devem ser copiadas. Em fundições, quer seja para fins de engenharia ou artísticos, o objeto do qual se deve tirar um molde normalmente é criado primeiro em algum material que pode ser facilmente trabalhado, em geral madeira. A forma desse modelo é reproduzida em argila ou argamassa e derrama-se o metal fundido no molde assim obtido. $\mathrm{O}$ escultor faz inicialmente um modelo do objeto que deseja esculpir em algum material plástico, como cera, e depois 
emprega artifícios engenhosos e complicados para transferir esse modelo de cera, fiel à natureza, para a pedra em que o trabalho final será executado. Em anatomia e fisiologia, os modelos são empregados especialmente como auxiliares no ensino e nos estudos, e o método de modelagem ou cromoplastídio produz impressões excelentes de organismos vivos e permite a cópia de formas e cores em preparações anatômicas e médicas. Usa-se também um método especial para fazer modelos plásticos de objetos microscópicos. Para que sua natureza e estrutura internas possam ser mais facilmente estudadas, eles são divididos em vários cortes transversais paralelos, com seções extremamente finas, usando-se um micrótomo. Cada uma dessas fatias é modelada em uma escala ampliada em lâminas de cera ou polpa que são fixadas juntas para formar uma reprodução do objeto.

\section{RepresentaçÃo no Pensamento}

Os modelos são de grande importância nas ciências matemáticas, físicas e mecânicas. Há muito tempo a filosofia percebeu a essência do processo de pensamento, que consiste no fato de que, aos vários objetos reais à nossa volta, associamos atributos físicos particulares - conceitos - e, por meio deles, tentamos representar os objetos nas nossas mentes. Outrora, os matemáticos e físicos consideravam tais visões como nada além de especulações improdutivas, mas recentemente eles foram levados por J. C. Maxwell, H. v. Helmholtz, E. Mach, H. Hertz e muitos outros a uma proximidade maior com o conteúdo integral das teorias matemáticas e físicas. Nessa perspectiva, os pensamentos representam coisas na mesma relação pela qual os modelos representam objetos. A essência do processo é a associação de um conceito que tem um conteúdo definido a cada coisa, mas sem implicar uma similaridade completa entre a coisa e o pensamento. Naturalmente só podemos saber pouco da semelhança de nossos pensamentos com as coisas às quais os associamos. A semelhança que há encontra-se, sobretudo, na natureza da conexão, sendo a correlação análoga àquela que se obtém entre o pensamento e a linguagem, a linguagem e a escrita, as notas na pauta e os sons musicais etc. É claro que aqui a simbolização da coisa é o ponto importante, embora se vise, onde exequível, a máxima correspondência possível entre os dois - um exemplo é a escala musical, que é imitada quando se usam as notas mais altas ou baixas. Quando, portanto, empenhamo-nos para instrumentalizar nossas concepções de espaço com figuras, usando os métodos da geometria descritiva e vários modelos de linha e objeto, nossa topografia, com plantas, mapas e globos, e nossas ideias mecânicas e físicas, com modelos cinemáticos, estamos simplesmente estendendo e continuando o princípio por meio do qual compreendemos os objetos no pensamento e os representamos na lin- 
guagem ou na escrita. Exatamente da mesma forma o microscópio ou o telescópio continua e multiplica as lentes do olho e o caderno de notas representa uma expansão externa do mesmo processo que a memória realiza de modo exclusivamente interno. Há também um óbvio paralelismo com a representação por meio de modelos quando expressamos a longitude, a milhagem, a temperatura etc. com números, que deveriam ser considerados como analogias aritméticas. De um tipo semelhante é a representação de distâncias com linhas retas, da trajetória de eventos no tempo com curvas etc. Entretanto não podemos falar legitimamente de modelos nem nesse caso, nem no de mapas, diagramas, notas musicais, figuras etc., já que eles envolvem uma analogia espacial concreta em três dimensões.

Enquanto o volume de material com o qual a ciência lidava era insignificante, a necessidade de empregar modelos era naturalmente menos imperativa; na verdade, há vantagens evidentes em compreender as coisas sem recorrer a modelos complicados, que são difíceis de fazer e não podem ser alterados e adaptados a condições extremamente variadas de maneira tão fácil quanto são os símbolos do pensamento, da concepção e do cálculo. No entanto, conforme os fatos da ciência aumentaram em número, foi necessário observar uma maior economia de esforço para abrangê-los e transmitilos aos outros, e o sólido estabelecimento de demonstrações visuais foi inevitável, em vista de sua enorme superioridade sobre o simbolismo exclusivamente abstrato, para obter uma rápida e completa exibição de relações complicadas. Atualmente é desejável, por um lado, que o poder de deduzir resultados de premissas puramente abstratas, sem recorrer à ajuda de modelos tangíveis, seja mais aperfeiçoado; por outro lado, é desejável que concepções puramente abstratas sejam auxiliadas por modelos objetivos e abrangentes nos casos em que a quantidade de material não possa ser direta e adequadamente tratada.

\section{Modelos NA MATEMÁtica E NA FÍSica}

Na matemática pura, especialmente na geometria, os modelos construídos de papel machê e argamassa são empregados, sobretudo para apresentar aos sentidos a forma precisa de figuras geométricas, superfícies e curvas. As superfícies de segunda ordem, representadas por equações de segundo grau entre as coordenadas retangulares de um ponto, são muito simples de classificar e, portanto, todas as suas possíveis formas podem ser facilmente apresentadas com alguns modelos. Isso fica um pouco mais complicado quando linhas de curvatura, loxodrômicas e geodésicas, precisam aparecer em suas superfícies. Por outro lado, a multiplicidade de superfícies de terceira ordem é enorme e, para transferir seus tipos fundamentais, é necessário empregar vários mo- 
delos de construção complicada, para não dizer arriscada. No caso de superfícies mais complexas, basta apresentar aquelas singularidades que apresentam variação do tipo usual de superfície com curvaturas, sinclástica ou anticlástica, como uma borda ou ponta afiada, ou uma interseção da superfície com ela mesma. A elucidação de tais singularidades é de importância fundamental na matemática moderna.

$\mathrm{Na}$ ciência física, igualmente, modelos de forma imutável são amplamente empregados. Por exemplo, a operação de refração da luz em cristais pode ser descrita se imaginarmos um ponto no centro do cristal de onde a luz é disseminada em todas as direções. O conjunto de lugares em que a luz chega a qualquer instante após o início dessa operação é chamado de frente de onda (wave-front). Essa superfície é composta por duas ventosas (cups) ou lâminas (sheets) que se ajustam firme e exatamente uma à outra. Os dois raios em que um raio simples é dividido são sempre determinados pelos pontos de contato de certos planos tangentes representados naquelas lâminas. Com os cristais possuindo dois eixos, essas superfícies de onda apresentam singularidades peculiares no sentido já mencionado do termo: a lâmina interna tem quatro protuberâncias, enquanto a externa tem quatro depressões semelhantes a funis, sendo que o ponto mais baixo de cada depressão encontra o ponto mais alto de cada protuberância. Em cada um desses funis há um plano tangente que é tocado não em um único ponto, mas em um círculo que limita a depressão, de modo que o raio de luz correspondente seja refletido não em dois raios, mas em um cone inteiro de luz. Esta é a chamada refração cônica, prevista teoricamente por Sir W. R. Hamilton e detectada experimentalmente por Humphrey Lloyd. Essas condições, que são difíceis de expressar adequadamente pela linguagem, são autoevidentes assim que a superfície de onda formada na argamassa encontra-se diante de nossos olhos. Na termodinâmica, modelos similares também servem, dentre outros fins, para representar superfícies que apresentam a relação entre as três variáveis termodinâmicas de um corpo, por exemplo, entre sua temperatura, pressão e volume. Uma olhada no modelo de tal superfície termodinâmica permite perceber imediatamente o comportamento de uma determinada substância sob as mais variadas condições. Quando a ordenada corta a superfície somente uma vez, apenas uma fase do corpo é concebível, no entanto, onde há uma interseção múltipla, várias fases são possíveis, podendo ser líquidas ou gasosas. Nos limites entre essas regiões encontram-se as fases críticas, onde a transição ocorre de um tipo de fase para outro. Caso se escolha uma quantidade que ocorre na calorimetria para um dos elementos, a entropia, por exemplo, também são obtidas as informações sobre o comportamento do corpo quando o calor é calculado ou abstrato.

Depois dos modelos imóveis até aqui considerados, seguem-se as formas complexas de modelos móveis, como as que são usadas na geometria para mostrar a origem das figuras geométricas a partir do movimento de outras - por exemplo, a origem das 
superfícies a partir do movimento das linhas. Isso inclui modelos de linha em que as linhas são desenhadas firmemente entre objetos móveis, tais como barras, fios, rodas, cilindros etc. Na mecânica e engenharia, emprega-se uma variedade sem fim de modelos de trabalho para que seja possível visualizar o funcionamento das máquinas como um todo ou de seus componentes e peças secundárias. Na mecânica teórica, os modelos são usados frequentemente para exibir as leis físicas do movimento em casos interessantes ou especiais - por exemplo, o movimento de um corpo em queda ou de um pião, o movimento de um pêndulo em função da rotação da Terra, os movimentos em vórtices dos fluidos etc. Assim como esses, há também os modelos que executam mais ou menos exatamente os movimentos hipotéticos por meio dos quais se pretende explicar os vários fenômenos físicos - por exemplo, as complicadas máquinas de onda (wave-machines) que apresentam o movimento das partículas como ondas de som (agora verificadas com mais precisão), ou o movimento hipotético dos átomos de éter em ondas de luz.

\section{TEORIAS DA NATUREZA}

A importância variável que recentemente se associa a modelos desse tipo está intimamente ligada às mudanças que vêm ocorrendo em nossas concepções de natureza. O primeiro método pelo qual se tentou resolver o problema do universo estava totalmente sob a influência das leis de Newton. Em analogia com as suas leis da gravitação universal, todos os corpos eram concebidos como compostos de pontos materiais átomos ou moléculas - aos quais era atribuída uma ação direta a distância. As circunstâncias dessa ação a distância, entretanto, foram concebidas diferentemente daquelas da lei de atração newtoniana, na qual elas poderiam explicar as propriedades não apenas de corpos elásticos sólidos, mas também de fluidos tanto líquidos quanto gasosos. Os fenômenos do calor eram explicados pelo movimento de partículas minúsculas absolutamente invisíveis a olho nu, enquanto para explicar os fenômenos da luz assumia-se que um meio impalpável, chamado de éter luminífero, permeava todo o universo. A ele foram atribuídas as mesmas propriedades dos corpos sólidos e também se supunha que era constituído de átomos, embora de uma composição bem menor. Para explicar os fenômenos elétricos e magnéticos, admitiu-se uma terceira espécie de matéria - fluidos elétricos, que eram concebidos como sendo mais da natureza dos fluidos, mas ainda compostos de partículas infinitesimais, também atuando diretamente umas sobre as outras a distância. Essa primeira fase da física teórica pode ser chamada de direta, já que toma como principal objeto a investigação da estrutura interna da matéria como ela realmente existe. Ela também é conhecida como teoria me- 
cânica da natureza, já que busca remontar às origens de todos os fenômenos naturais até os movimentos das partículas infinitesimais, ou seja, até os fenômenos puramente mecânicos. Ao explicar os fenômenos magnéticos e elétricos, é inevitável recair em hipóteses um tanto artificiais e improváveis, e isso induziu J. Clerk Maxwell, adotando as ideias de Michael Faraday, a propor uma teoria de fenômenos elétricos e magnéticos que não só era nova em substância, mas também essencialmente diferente na forma. Se os átomos e moléculas da teoria antiga não eram para ser concebidos como pontos matemáticos exatos no sentido abstrato, então suas verdadeiras natureza e forma deveriam ser consideradas como absolutamente desconhecidas, e seus agrupamentos e movimentos, exigidos pela teoria, deveriam ser estimados simplesmente como um processo mais ou menos parecido com o funcionamento da natureza e representando mais ou menos exatamente certos aspectos incidentais desse funcionamento. Com isso em mente, Maxwell propôs determinadas teorias físicas que eram exclusivamente mecânicas até onde elas se originavam de uma concepção de processos puramente mecânicos. Mas ele estabeleceu de modo explícito que não acreditava na existência de agentes mecânicos assim constituídos na natureza, e que os considerava apenas como meios pelos quais os fenômenos poderiam ser reproduzidos, guardando certa similaridade com aqueles que realmente existem, e que também servem para incluir maiores grupos de fenômenos de uma maneira uniforme e para determinar as relações que possuem em seu caso. Quando a questão deixa de ser a verificação da estrutura interna real da matéria, muitas analogias mecânicas ou ilustrações dinâmicas tornam-se disponíveis com diferentes vantagens. Na verdade, Maxwell empregou primeiro arranjos mecânicos especiais e complicados, embora depois eles tenham sido tornados mais gerais e indefinidos. Essa teoria - assim são chamadas as analogias mecânicas - conduz à construção de vários modelos mecânicos. O próprio Maxwell e seus seguidores planejaram muitos modelos cinemáticos, projetados para oferecer uma representação da construção mecânica do éter como um todo, bem como dos mecanismos separados que funcionam nele: esses modelos são parecidos às velhas máquinas de ondas, até onde eles representam os movimentos de um mecanismo puramente hipotético. No entanto, embora antigamente se acreditasse que era tolerável assumir com um grande indício de probabilidade a existência real de tais mecanismos na natureza, atualmente os filósofos postulam que não há nada além de uma semelhança parcial entre o fenômeno visível em tais mecanismos e aqueles que aparecem na natureza. Aqui de novo fica perfeitamente claro que esses modelos de madeira, metal e papelão são realmente uma continuação e integração de nosso processo de pensamento. De acordo com a perspectiva em questão, a teoria física é meramente uma construção mental de modelos mecâ- 
nicos, cujo funcionamento nós mesmos planejamos por meio da analogia com mecanismos que seguramos em nossas mãos, e que, por terem tanto em comum com os fenômenos naturais, podem ajudar-nos a compreendê-los.

Embora Maxwell tenha desistido da ideia de fazer uma investigação precisa da estrutura final da matéria tal como ela realmente é, seu trabalho foi ainda mais além, conduzido por G. R. Kirchhoff agora na Alemanha. Kirchhoff definiu seu próprio objetivo como sendo descrever, e não explicar, o mundo do fenômeno, mas, dado que ele não explica como fazer isso, sua teoria difere um pouco da teoria de Maxwell tão logo recorre à descrição usando modelos mecânicos e analogias. Agora que os recursos da matemática pura vêm sendo ajustados particularmente à descrição exata das relações quantitativas, a escola de Kirchhoff deu grande ênfase à descrição por meio de expressões e fórmulas matemáticas, e o objetivo da teoria física passou a ser considerado, sobretudo, como sendo a construção de fórmulas por meio das quais os fenômenos nos vários ramos da física devem ser determinados com a maior aproximação da realidade. Essa visão da natureza da teoria física é conhecida como fenomenologia matemática; trata-se de uma apresentação do fenômeno por meio de analogias, embora somente por meio de analogia possa ser chamada matemática.

Outra fenomenologia no sentido mais amplo do termo, defendida principalmente por E. Mach, concede menos importância à matemática, mas considera que foi muito rapidamente adotada a concepção segundo a qual os fenômenos de movimento são essencialmente os mais fundamentais de todos. Ele também enfatiza a maior importância da descrição nos termos mais gerais das várias esferas de fenômenos e sustenta que se apliquem sua própria lei fundamental e as noções daí derivadas a cada esfera. Essa teoria considera o uso de analogias e elucidações de uma esfera por outra - por exemplo, calor, eletricidade etc. por concepções mecânicas - como meros auxiliares à percepção, que são necessários ao desenvolvimento histórico, mas que, ao longo do tempo, dão lugar a outros ou desaparecem totalmente do domínio da ciência.

Todas essas teorias são contrárias a outra que se chama energética (no sentido mais restrito), que considera a concepção de energia, e não a matéria, como a noção fundamental de toda a pesquisa científica. Ela se fundamenta essencialmente nas similaridades que a energia apresenta em suas várias esferas de ação, mas ao mesmo tempo toma uma posição firme sobre uma interpretação ou explicação dos fenômenos naturais por analogias que, entretanto, não são mecânicas, mas lidam com o comportamento da energia em seus vários modos de manifestação. 


\section{Modelos EXPERIMENTAis}

Deve-se observar uma distinção entre os modelos que foram descritos e aqueles modelos experimentais que apresentam, em escala reduzida, uma máquina que será posteriormente finalizada em uma máquina maior, de modo a oferecer uma prova de suas capacidades. É necessário notar aqui que uma mera alteração nas dimensões normalmente é suficiente para causar uma alteração material na ação, já que as diversas capacidades dependem de maneiras variadas das dimensões lineares. Por exemplo, o peso varia como o cubo das dimensões lineares, a superfície de qualquer peça simples e os fenômenos que dependem de tais superfícies são proporcionais ao quadrado, ao passo que outros efeitos - tais como o atrito, a expansão, a condução de calor etc. - variam de acordo com outras leis. Uma máquina voadora, portanto, que quando feita em pequena escala é capaz de suportar seu próprio peso, perde seu poder quando suas dimensões são aumentadas. A teoria, iniciada por Sir Isaac Newton, da dependência que os vários efeitos apresentam em relação às dimensões lineares, é tratada no artigo UnIDADEs, Dimensões da (Units, Dimensions of). Em condições simples, pode-se afirmar frequentemente que, em comparação com uma máquina grande, uma máquina pequena tem a mesma capacidade em relação a um padrão de tempo que deve ser reduzido em uma certa proporção.

É claro que os modelos experimentais não são apenas aqueles em que se empregam exclusivamente forças mecânicas, mas também incluem modelos de mecanismos térmicos, eletromagnéticos e outros, por exemplo, dínamos e máquinas telegráficas. A maior coleção de tais modelos encontra-se no museu do Escritório de Patentes de Washington. Às vezes, para fins de pesquisa e instrução, os modelos funcionam com forças que não são exclusivamente mecânicas. Regularmente, uma série de processos naturais - tais como o movimento de líquidos, o atrito interno dos gases e a condução de calor e eletricidade em metais - pode ser expressa pelas mesmas equações diferenciais e é possível, com a mesma frequência, seguir um desses processos em questão por meio de medições - por exemplo, a condução de eletricidade mencionada. Se um modelo revelar um caso particular de condução elétrica no qual as mesmas condições mantêm-se no limite, como em um problema de atrito interno dos gases, poderemos determinar imediatamente, por meio de uma medição da condução elétrica no modelo, os dados numéricos que se obtêm para casos análogos de atrito interno, e que, de outro modo, só poderiam ser verificados por cálculos complexos. Ademais, os cálculos complicados podem ser dispensados frequentemente com a ajuda de dispositivos mecânicos, tais como as engenhosas máquinas de calcular que realizam adições e subtrações, além de multiplicações e divisões bastante elaboradas, com velocidade e preci- 
Modelo

são surpreendentes, ou os mecanismos para resolver equações mais complexas, determinar o volume ou a área de figuras geométricas, realizar integrações e desenvolver uma função em uma série de Fourier por meios mecânicos.

Traduzido do original em inglês por Cristina de Amorim Machado. Revisão técnica de Antonio Augusto Passos Videira e Tatiana Roque.

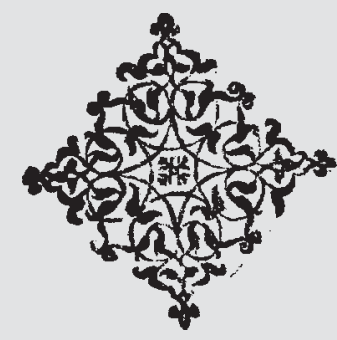

